\title{
The effect of tube versus bottle feeding colostrum on immunoglobulin G absorption, abomasal emptying, and plasma hormone concentrations in newborn calves
}

\author{
M. Desjardins-Morrissette, ${ }^{*}$ J. K. van Niekerk, ${ }^{*}$ D. Haines, $†$ T. Sugino, $\ddagger$ M. Oba, ${ }^{* 1}$ and M. A. Steele ${ }^{* 1}$ \\ *Department of Agricultural, Food and Nutritional Science, University of Alberta, Edmonton, AB T6G 2P5, Canada \\ †The Saskatoon Colostrum Co. Ltd., Saskatoon, Canada S7K 6A2 \\ $\ddagger$ The Research Center for Animal Science, Graduate School of Biosphere Science, Hiroshima University, Higashi-Hiroshima, Japan 739-8528
}

\begin{abstract}
The objective of this study was to determine if feeding colostrum to newborn calves through an esophageal tube, compared with a nipple bottle, would delay abomasal emptying, which would in turn decrease passive transfer of $\operatorname{IgG}$ and plasma glucose, insulin, and glucagon-like peptide (GLP) 1 and GLP-2 concentrations. Twenty newborn Holstein bull calves were fed 3 L of colostrum replacer (200 g of $\operatorname{IgG}$ ) through either an esophageal tube or nipple bottle at $2 \mathrm{~h}$ after birth followed by feeding pooled whole milk every $12 \mathrm{~h}$ after birth. Acetaminophen was mixed into the colostrum meal as a marker for abomasal emptying. A jugular catheter was inserted $1 \mathrm{~h}$ after birth and blood was sampled frequently to analyze serum for IgG and acetaminophen and plasma for glucose, insulin, GLP-1, and GLP-2. Feeding method did not affect abomasal emptying, and as a result no treatment effect was present on serum IgG concentrations. Maximum concentration of serum IgG was $24.4 \pm 0.40 \mathrm{mg} / \mathrm{mL}$ ( \pm standard error), which was reached at $14.6 \pm 1.88 \mathrm{~h}$ after the colostrum meal for both groups. Apparent efficiency of absorption at maximum concentration of $\mathrm{IgG}$ was $52.9 \%$, indicating high efficiency of passive transfer of $\mathrm{IgG}$ for both treatments. Tube feeding increased glucose and insulin area under the curve before the first milk meal, most likely due to the decreased time to consume the colostrum meal. In addition, tube-fed calves consumed $0.5 \pm$ $0.13 \mathrm{~L}$ more milk in their first milk meal than bottle-fed calves. No treatment effect on plasma concentrations of GLP-1 or GLP-2 was present, but both hormones increased after colostrum feeding. These findings confirm that there is no effect on absorption of IgG from colostrum when feeding good-quality colostrum at a
\end{abstract}

Received September 26, 2017.

Accepted December 23, 2017.

${ }^{1}$ Corresponding authors: masteele@ualberta.ca and moba@ ualberta.ca volume of $3 \mathrm{~L}$ through either an esophageal tube or nipple bottle.

Key words: colostrum, calf, feeding, gastric function

\section{INTRODUCTION}

Unlike primates, cows do not transfer immunoglobulin to their calves in utero, which results in calves being born essentially agammaglobulinemic (reviewed in Godden, 2008). Calves acquire maternal immunoglobulins through colostrum, and thus proper colostrum management is critical to ensure adequate passive transfer of immunity. Failure of passive transfer of immunity, defined as a calf having less than $10 \mathrm{~g} / \mathrm{L}$ of serum IgG between 24 and $48 \mathrm{~h}$ of age, occurs frequently on dairy farms (Godden, 2008). The prevalence of failure of passive transfer of immunity has been shown to be as high as $19.2 \%$ of dairy heifer calves in the United States and 25 to $37 \%$ of calves in Canada, indicating that colostrum management on farms can be improved (Wallace et al., 2006; Trotz-Williams et al., 2008; Beam et al., 2009).

Current industry practices include feeding colostrum through either an esophageal tube or a nipple bottle. Feeding with an esophageal tube is a more time-efficient feeding method, whereas feeding with a nipple bottle is a more natural feeding method. Godden et al. (2009) found that feeding colostrum with a nipple bottle increased serum concentrations of IgG when calves were fed $1.5 \mathrm{~L}$ of colostrum, compared with an esophageal tube, but no difference was observed between treatments when 3 L of colostrum was fed. Kaske et al. (2005) found that absorption of IgG was delayed by $3 \mathrm{~h}$ when feeding $4 \mathrm{~L}$ with an esophageal tube compared with $2 \mathrm{~L}$ with a nipple bottle. These differences in amount and timing of IgG absorption might be due to colostrum entering the rumen when fed with an esophageal tube, which would delay colostrum reaching the small intestine for IgG absorption (Sharifi et al., 2009). Previous studies have not measured the abomasal emptying rate when fed with a tube, or abomasal emptying rate to 
determine if feeding method affects timing of nutrients reaching the small intestine. In addition, other studies comparing tube or bottle feeding only measured serum IgG concentrations, which overlooked the critical role that other factors in colostrum play in metabolic and gut development in newborn calves (Blum and Hammon, 2000).

Colostrum feeding has been shown to improve glucose metabolism in newborn calves (Hammon and Blum, 1998). In particular, colostrum is necessary for development of the gluconeogenic pathway (Steinhoff-Wagner et al., 2011). Calves that receive colostrum have higher plasma glucose and insulin concentrations in response to milk feedings, indicating a greater glucose response compared with calves that were not fed colostrum (Hammon and Blum, 1998; Kühne et al., 2000). Lower abomasal emptying rates was associated with lower plasma glucose concentrations (MacPherson et al., 2016), indicating that delaying delivery of colostrum to the small intestine could also decrease plasma glucose and insulin concentrations.

Colostrum feeding is also associated with increased gut development in newborn calves (Blum and Hammon, 2000). Gut peptide hormones, GLP-1 and GLP-2, have been demonstrated to have beneficial effects in calves (Taylor-Edwards et al., 2011; Fukumori et al., 2012a). Intravenous treatment of GLP-1 was shown to increase plasma insulin while decreasing plasma glucose concentrations both pre- and postweaning (Fukumori et al., 2012a), whereas treatment of GLP-2 was shown to increase epithelial mass, villus height, and crypt depths (Taylor-Edwards et al., 2011). The benefits associated with GLP-1 and GLP-2 following colostrum feeding have yet to be studied in newborn calves, and because their secretion is stimulated by nutrients reaching the lower gut, feeding method could affect concentrations of these hormones (Holst, 2000).

The hypothesis of this study was that feeding colostrum with an esophageal tube compared with a nipple bottle would decrease abomasal emptying rate, delay colostrum reaching the small intestine, and thus delay or decrease absorption of IgG, plasma concentrations of glucose, insulin, GLP-1, and GLP-2. The specific objectives of this study were to determine if feeding colostrum with an esophageal tube would affect abomasal emptying rates, serum $\mathrm{IgG}$, and plasma concentrations of glucose, insulin, GLP-1, and GLP-2.

\section{MATERIALS AND METHODS}

\section{Animals}

Prior to the study, it was determined using gastric emptying and serum IgG data that a total of 10 calves were required per treatment to detect a $25 \%$ difference with an $80 \%$ statistical power (Berndtson, 1991). Therefore, 20 Holstein bull calves (birth BW $=44.8 \pm$ $4.13 \mathrm{~kg}$; mean $\pm \mathrm{SD}$ ) from a commercial dairy (Millet, Alberta, Canada) were selected for this study (2 treatments described below); eligible calves were single birthed with a calving ease score of $\leq 3$, using Lombard et al. $(2007 ; 1$ to 5 scale with $1=$ no assistance, $2=$ assistance by one person without mechanical extraction, $3=$ assistance by 2 or more people, $4=$ mechanical extraction used and $5=$ surgical). In addition, calves were required to consume $3 \mathrm{~L}$ of colostrum (one bottle-fed calf voluntarily consumed $2.5 \mathrm{~L}$ of colostrum, and the rest were tube fed) and at least $50 \%$ of their milk meals to remain eligible for the study. They were removed from the dam within 10 min after birth, weighed, and housed in individual pens bedded with straw and then dried off for $20 \mathrm{~min}$. This study was approved by the University of Alberta Animal Care and Use Committee for Livestock (AUP 00001890) according to the guidelines of the Canadian Council of Animal Care (CCAC, 1993).

\section{Feeding}

Calves were randomly assigned to a treatment of nipple bottle or esophageal tube and given their colostrum meal through either feeding method at $2 \mathrm{~h}$ after birth. All calves were fed $750 \mathrm{~g}$ of colostrum replacer powder (Headstart, Saskatoon Colostrum Company Ltd., Saskatoon, SK, Canada) mixed with water to reach a final volume of $3 \mathrm{~L}$ to deliver $200 \mathrm{~g}$ of $\mathrm{IgG}$. Calves were given $30 \mathrm{~min}$ to consume their colostrum meal. Bottle-fed calves that refused $<500 \mathrm{~mL}$ were tubed the remainder of their colostrum meal, which only occurred with 1 calf. Time to consume the colostrum meal was recorded for each calf. The first milk meal was offered at $12 \mathrm{~h}$ of life and every $12 \mathrm{~h}$ thereafter until the end of the study at $48 \mathrm{~h}$ of life. All calves received $3 \mathrm{~L}$ of pasteurized whole milk at each feeding from a pooled source that was pasteurized, frozen, and then thawed before feeding. Calves were given $30 \mathrm{~min}$ to consume their milk meals and any refusals were recorded.

\section{Sample Collection}

A 16-gauge jugular catheter (Thermo Fisher Scientific, San Diego, CA) was placed in each calf $1 \mathrm{~h}$ after birth. Three attempts to insert the catheter on each side of the calf's neck could be made with the catheter before the end point for catheterization attempts was reached and the calf removed from the study. One calf was removed from the study due to this criterion. Acetaminophen was added to the colostrum meal at 150 
$\mathrm{mg} / \mathrm{kg}$ of $\mathrm{BW}^{0.75}$ to estimate abomasal emptying rate by measuring kinetics of acetaminophen appearance in plasma. To determine serum acetaminophen concentrations, blood samples were collected at $-0.5,0.5,1.0$, $1.5,2.0,2.5,3.0,3.5,4.0,5.0,6.0,8.0$, and $10 \mathrm{~h}$ relative to colostrum feeding as described by Sen et al. (2006). To determine serum IgG and plasma glucose, insulin, GLP-1, and GLP-2 concentrations, a total of 22 blood samples were collected from each calf at $-1.0,-0.5,0$, $0.5,1.0,1.5,2.0,2.5,3.0,3.5,4.0,5.0,6.0$, and $8.0 \mathrm{~h}$ relative to feeding of the colostrum meal and at 12,15 , $18,24,30,36,42$, and $48 \mathrm{~h}$ of life.

After each blood collection, catheters were flushed with $6 \mathrm{~mL}$ of saline solution and the extension of the catheter and the catheter itself were filled with $1.5 \mathrm{~mL}$ of $2 \%$ heparinized saline solution to fill the catheter line. Before each sample collection, a small portion (1.5 $\mathrm{mL}$ ) was discarded to remove any residual flush in the catheter line. Ten milliliters of blood was collected at each sampling, $5 \mathrm{~mL}$ into a heparinized tube that was inverted 5 times, placed on ice immediately followed by the addition of $2.5 \mu \mathrm{L}$ of aprotinin $(100 \mu \mathrm{g} / \mathrm{mL})$ into the tube before centrifuging the sample at $3,000 \times g$ for $20 \mathrm{~min}$ at room temperature. The plasma was collected and aliquoted into three $1.5-\mathrm{mL}$ microcentrifuge tubes and immediately frozen at $-20^{\circ} \mathrm{C}$. The remaining $5 \mathrm{~mL}$ of blood was placed into a red-top Vacutainer tube to harvest serum, these tubes were kept at room temperature for $3 \mathrm{~h}$ before centrifugation at $3,000 \times g$ for 20 min at room temperature. The serum was aliquoted into three $1.5-\mathrm{mL}$ microcentrifuge tubes and immediately frozen at $-20^{\circ} \mathrm{C}$.

\section{Sample Analyses}

Serum samples were analyzed for IgG concentration using the radial immunodiffusion method as described by Chamorro et al. (2014). Serum samples were analyzed for acetaminophen concentration in duplicate using the enzymatic Paracetamol Assay Kit-K8002 (Cambridge Life Sciences Ltd., Ely, UK). Plasma samples were analyzed in triplicate for glucose concentration using a glucose oxidase/peroxidase enzyme and dianisidine dihydrochloride (Sigma, St. Louis, MO) and absorbance at $450 \mathrm{~nm}$ was measured using a SpectraMax 190 plate reader (Molecular Devices Corp., Sunnyvale, CA). Plasma concentrations of insulin, GLP-1, and GLP-2 were analyzed using the time-resolved fluoroimmunoassay method (competitive solid-phase immunoassay) as described by Fukumori et al. (2012b). Intra- and interassay coefficients of variation for insulin, GLP-1, and GLP-2 were 2.2 and 1.8\%, 1.7 and $4.8 \%$, and 2.7 and $2.2 \%$, respectively (Inabu et al., 2017).

\section{Calculations and Statistics}

The method used to determine abomasal emptying rate was as described by Cant et al. (2006). To calculate abomasal emptying rate, it was assumed that outflow from the abomasum followed first-order kinetics according to the rate constant $\mathrm{k}_{\mathrm{AB}}$, elimination from the blood followed first-order kinetics according to the rate constant $\mathrm{k}_{\mathrm{el}}$, and absorption into the blood from the small intestine was instantaneous. The differential equations describing the mass of acetaminophen in the abomasum (A) and in the blood (B) are

$$
\frac{\mathrm{dA}}{\mathrm{dt}}=-\mathrm{k}_{\mathrm{AB}} \mathrm{A},
$$

and

$$
\frac{\mathrm{dB}}{\mathrm{dt}}=\mathrm{k}_{\mathrm{AB}} \mathrm{A}-\mathrm{k}_{\mathrm{el}} \mathrm{B}
$$

respectively. These equations are integrated and the concentration of acetaminophen in the blood at time $t$ $\left(\mathrm{cB}_{\mathrm{t}}\right)$ becomes

$$
\mathrm{cB}_{\mathrm{t}}=\frac{\text { Dose } \cdot \mathrm{k}_{\mathrm{AB}}}{\mathrm{k}_{\mathrm{AB}} \cdot \mathrm{k}_{\mathrm{el}}}\left(\mathrm{e}^{-\mathrm{k}_{\mathrm{el}} \cdot \mathrm{t}}-\mathrm{e}^{-\mathrm{k}_{\mathrm{AB}} \cdot \mathrm{t}}\right) .
$$

The software JMP 13 (SAS Institute Inc., Cary, NC) was used to estimate $\mathrm{k}_{\mathrm{AB}}$ and $\mathrm{k}_{\mathrm{el}}$ by fitting Equation [3] to the observed blood concentration curves for each calf.

For IgG, glucose, insulin, GLP-1, and GLP-2, the maximum concentration $\left(\mathbf{C}_{\max }\right)$, time to reach maximum concentration $\left(\mathbf{T}_{\max }\right)$ and area under the curve (AUC) was calculated from the raw data. Area under the curve was calculated using the trapezoid rule and was calculated over the entire sampling period. Apparent efficiency of absorption (AEA, \%) of IgG was calculated using the formula previously described by Quigley et al. (2002), assuming that plasma volume is $9.9 \%$ of birth BW.

Treatment effect for BW, feeding time, milk consumed, $\mathrm{C}_{\max }, \mathrm{T}_{\max }$, AUC, AEA, $\mathrm{k}_{\mathrm{AB}}$, and $\mathrm{k}_{\mathrm{el}}$ was analyzed using 1-way ANOVA method of JMP 13. Effects of treatment, time as a repeated measure, and the treatment $\times$ time interaction were analyzed for $\operatorname{IgG}$, glucose, insulin, GLP-1, and GLP-2 data using the Fit Model method of JMP 13. The covariance structure used for repeated measures was compound symmetry with significance declared when $P \leq 0.05$ and tendencies declared when $P<0.10$ but $>0.05$. 
Table 1. Effect of tube versus bottle feeding colostrum on time to consume colostrum and amount of milk consumed in newborn calves

\begin{tabular}{|c|c|c|c|c|}
\hline \multirow[b]{2}{*}{ Item } & \multicolumn{2}{|c|}{ Treatment } & \multirow[b]{2}{*}{ SEM } & \multirow[b]{2}{*}{$P$-value } \\
\hline & Bottle & Tube & & \\
\hline Time to consume colostrum (min) & 17.6 & 5.2 & 1.51 & $<0.0001$ \\
\hline Amount of milk, first meal (L) & 2.47 & 2.96 & 0.130 & 0.01 \\
\hline Amount of milk, second meal (L) & 2.96 & 2.97 & 0.035 & 0.84 \\
\hline Amount of milk, third meal (L) & 2.90 & 3.00 & 0.05 & 0.19 \\
\hline Amount of milk, fourth meal (L) & 3.00 & 3.00 & 0.00 & $\mathrm{NA}^{1}$ \\
\hline
\end{tabular}

${ }^{1} \mathrm{NA}=$ not applicable

\section{RESULTS}

\section{$B W$ and Feeding}

No difference was observed between treatments for $\mathrm{BW}(\mathrm{BW}=44.8 \pm 1.34 \mathrm{~kg} ; P=0.98)$. Time to consume the colostrum meal was shorter for the tube treatment than the bottle treatment $(P<0.0001$; Table 1$)$. Calves in the tube treatment consumed significantly more milk during the first milk meal than calves in the bottle treatment $(P=0.01$; Table 1$)$. No difference was observed between treatments for the remaining meals $(P>0.20)$, and in the last meal all calves consumed the full $3 \mathrm{~L}$ (Table 1). A strong negative correlation was observed between time to consume the colostrum meal and the amount of milk consumed in the first meal ( $\mathrm{r}$ $=-0.81, P<0.0001 ;$ Figure 1).

\section{IgG and Abomasal Emptying}

No treatment effect was present on IgG $\mathrm{C}_{\max }(P=$ $0.56), \mathrm{T}_{\max }(P=0.44)$, AEA $(P=0.84)$, or AUC $(P$ $=0.47$; Table 2$)$. In addition, no treatment effect $(P=$ $0.72)$ or treatment $\times$ time interaction $(P=0.92)$ was present for IgG serum concentrations, but a time effect $(P<0.0001$; Figure 2$)$ was present. Emptying rate was also not different between treatments $(P=0.96$; Table 2 ). A tendency was observed for abomasal emptying rate to be negatively correlated with GLP-1 $\mathrm{T}_{\max }(\mathrm{r}=$ $-0.41 ; P=0.08)$. No other correlations were observed for any other parameters with abomasal emptying rate.

\section{Glucose and Insulin}

No treatment effect $(P=0.49 ; P=0.12)$ or treatment $\times$ time interaction $(P=0.75 ; P=0.56)$ was observed for plasma concentrations of glucose and insulin, respectively (Figures 3 and 4). A time effect was present for plasma concentrations of glucose and insulin before the first milk meal $(P<0.0001)$, and an overall time effect on plasma concentrations was observed for glucose $(P<0.0001)$, but not for insulin $(P=0.72)$.
A tendency was observed for glucose $\mathrm{C}_{\max }$ to be higher for tube-fed calves compared with bottle-fed calves $(P$ $=0.06$; Table 3$)$. No treatment effect was observed on glucose $\mathrm{T}_{\max }(P=0.32)$, insulin $\mathrm{C}_{\max }(P=0.16)$, or insulin $\mathrm{T}_{\max }(P=0.91)$. When AUC was analyzed across the entire time period, the AUC for glucose was higher in tube-fed calves than in bottle-fed calves $(P$ $=0.03)$ and the AUC for insulin tended to be higher in tube-fed calves than in bottle-fed calves $(P=0.08)$. When AUC was analyzed separately for periods before and after the first milk meal, AUC for both glucose and insulin before the first milk meal was higher for tubefed calves $(P=0.02 ; P=0.02$, respectively). However, only glucose AUC after the first milk feeding tended to be higher for tube-fed calves $(P=0.06)$. No difference was observed between treatments for insulin AUC after the first milk meal $(P=0.14)$. Glucose and insulin AUC also tended to be positively correlated before the first milk meal $(\mathrm{r}=0.40, P=0.08)$, after the first milk meal $(\mathrm{r}=0.41, P=0.07)$, and for the overall period $(\mathrm{r}=0.40, P=0.08)$. In addition, glucose AUC before the first milk meal was negatively correlated with time to consume the colostrum meal $(\mathrm{r}=-0.60 ; P=0.005$; Figure 1) and positively correlated with the amount of milk consumed in the first milk meal $(\mathrm{r}=0.48 ; P=$ $0.03)$.

\section{GLP-1 and GLP-2}

No treatment effect $(P=0.26 ; P=0.43)$ or treatment $\times$ time interaction $(P=0.38 ; P=0.22)$ was observed for GLP-1 and GLP-2, respectively (Figures 5 and 6). An overall time effect was present for both GLP-1 and GLP-2 $(P<0.0001)$. No treatment effect was observed on $\mathrm{C}_{\max }(P=0.50 ; P=0.74), \mathrm{T}_{\max }(P=0.99 ; P=$ $0.20)$, or AUC $(P=0.28 ; P=0.21)$ for GLP-1 or GLP2 , respectively (Table 3 ). The plasma concentrations of GLP-1 and GLP-2 were positively correlated ( $\mathrm{r}=$ $0.53 ; P<0.0001)$. Also, a weak correlation was present between plasma concentrations of GLP-1 and insulin $(\mathrm{r}=0.23 ; P<0.0001)$, and GLP-1 AUC and insulin AUC tended to be positively correlated $(\mathrm{r}=0.39 ; P$ 


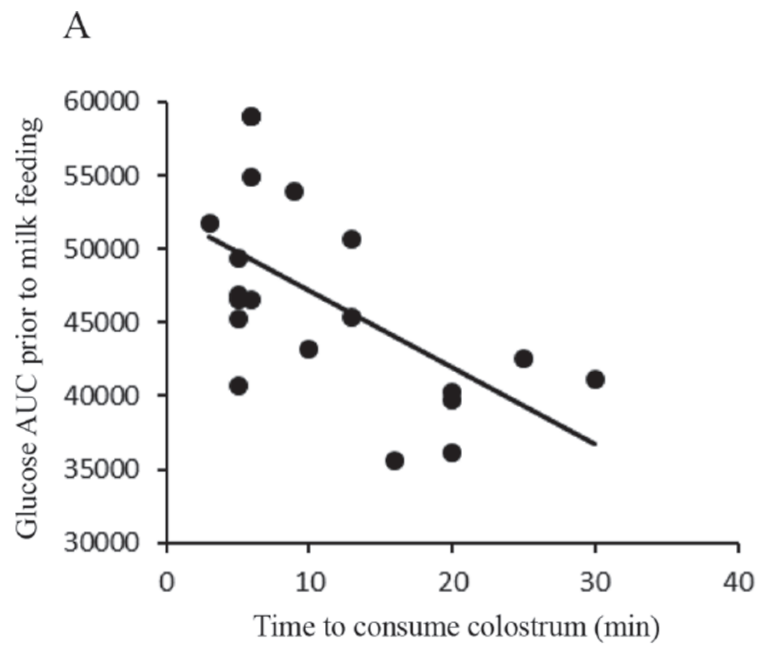

B

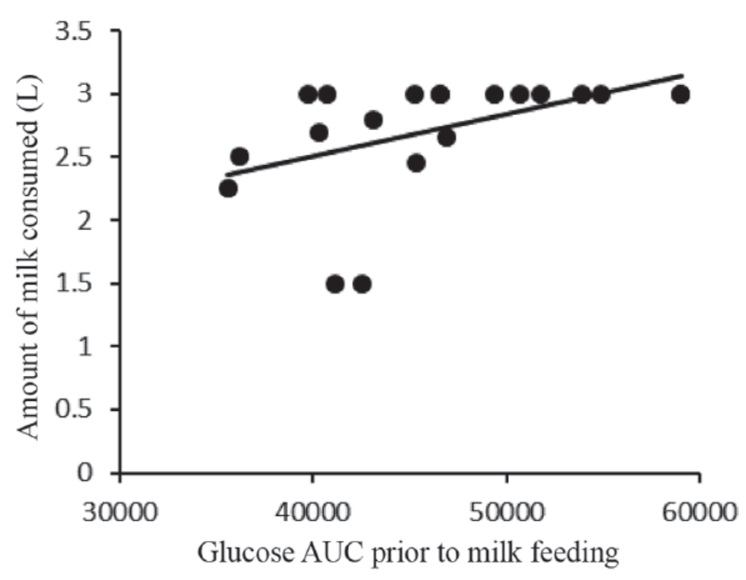

$\mathrm{C}$

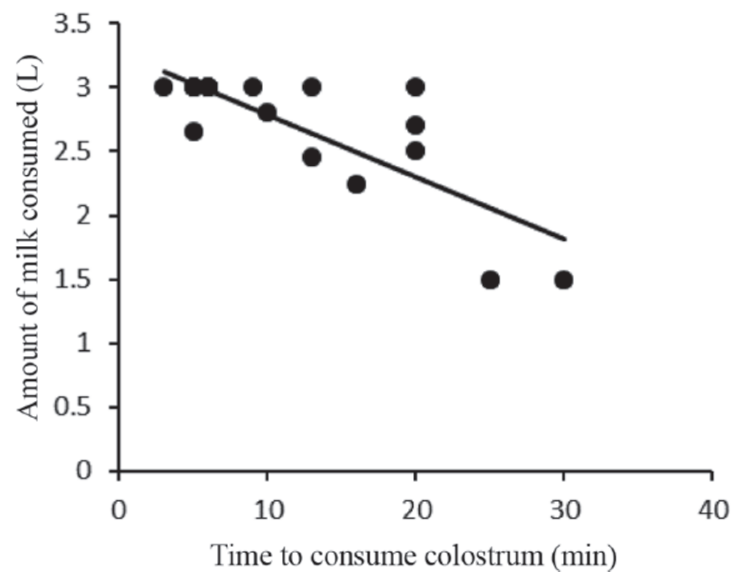

Figure 1. Coefficient of correlation between (A) time to consume the colostrum meal and glucose area under the curve (AUC) before the first milk feeding $(\mathrm{r}=-0.60 ; P=0.005)$, (B) amount of milk consumed in the first milk meal and glucose AUC before the first milk feeding ( $\mathrm{r}=0.48 ; P=0.03)$, and $(\mathrm{C})$ time to consume the colostrum meal and amount of milk consumed in the first milk meal $(\mathrm{r}=-0.81$; $P<0.0001)$.
$=0.09)$. In addition, time to consume the colostrum meal tended to be negatively correlated with GLP-1 and GLP-2 AUC before the first milk meal $(\mathrm{r}=-0.41$, $P=0.07 ; \mathrm{r}=-0.40, P=0.08$; respectively).

\section{DISCUSSION}

Previous research has shown conflicting results with regard to passive transfer of immunity between tubeand bottle-fed colostrum (Kaske et al., 2005; Godden et al., 2009; Chigerwe et al., 2012). Two studies suggest that colostrum may enter the rumen when fed with an esophageal tube, which would delay colostrum reaching the small intestine; however, emptying rates from the abomasum to the small intestine were not measured to support these speculations (Kaske et al., 2005; Godden et al., 2009). Because absorption of IgG from colostrum is time dependent, delays in reaching the small intestine could negatively affect both the rate and amount of absorption. Thus, the objective of this study was to determine if feeding colostrum with an esophageal tube would slow abomasal emptying, delay colostrum reaching the small intestine, and decrease serum concentrations of $\mathrm{IgG}$ and plasma concentrations of glucose, insulin, GLP-1, and GLP-2 compared with feeding with a nipple bottle.

\section{Abomasal Emptying and IgG}

The current study measured abomasal emptying using acetaminophen as a marker in accordance with previous studies (Marshall et al., 2005; Sen et al., 2006), and found no difference in emptying rates between the 2 feeding methods. Previous studies report that electrolyte solutions enter the rumen when fed with an esophageal tube due to failure to stimulate the reticular groove reflex; however, these studies used small volumes (Schaer et al., 2005; Nouri and Constable, 2006; Sharifi et al., 2009). The study conducted by Godden et al. (2009) found an increase in serum IgG concentrations in bottle-fed calves compared with tube-fed calves only when a small volume was fed. The current study fed a larger volume of $3 \mathrm{~L}$, which could explain the lack of difference in emptying rates between treatments. Chapman et al. (1986) demonstrated that the rumen of calves 1 to $17 \mathrm{~d}$ old retain up to $400 \mathrm{~mL}$ of liquid before it overflows to the abomasum. It is reasonable to assume that in newborn calves the rumen would hold less than $400 \mathrm{~mL}$ of colostrum; therefore, even if colostrum enters the rumen when feeding with an esophageal tube, less than $400 \mathrm{~mL}$ would remain. This means when a small volume is fed with a tube, a greater portion of the meal would remain in the rumen, whereas only a small portion of the meal would remain 
Table 2. Effect of tube versus bottle feeding colostrum on serum IgG concentrations and abomasal emptying rate in newborn calves

\begin{tabular}{|c|c|c|c|c|}
\hline \multirow[b]{2}{*}{ Item $^{1}$} & \multicolumn{2}{|c|}{ Treatment } & \multirow[b]{2}{*}{ SEM } & \multirow[b]{2}{*}{$P$-value } \\
\hline & Bottle & Tube & & \\
\hline $\operatorname{IgG~} \mathrm{C}_{\max }(\mathrm{mg} / \mathrm{mL})$ & 24.2 & 24.7 & 0.58 & 0.56 \\
\hline $\operatorname{IgG} \mathrm{T}_{\max }(\mathrm{h})$ & 13.1 & 16.1 & 2.68 & 0.44 \\
\hline IgG AUC $(\mathrm{mg} / \mathrm{mL} \times 46 \mathrm{~h})$ & 908.1 & 866.4 & 27.77 & 0.47 \\
\hline AEA $(\%)$ & 52.7 & 53.2 & 1.63 & 0.84 \\
\hline Abomasal emptying rate $(\% / \mathrm{h})$ & 52.4 & 52.9 & 7.50 & 0.96 \\
\hline
\end{tabular}
the concentration-time curve; AEA = apparent efficiency of absorption, $\mathrm{n}=10$ per group.

in the rumen when a large volume is fed and a greater proportion of the meal would flow past the rumen to the abomasum. Therefore, colostrum that enters the rumen is more likely to have a demonstrable effect on abomasal emptying rates only when small volumes are fed.

Consequently, because no difference was observed in abomasal emptying rates, no difference was present in serum IgG concentrations or AEA of IgG between the 2 treatments. It is likely that, when $3 \mathrm{~L}$ is fed, the majority of the meal would flow past the rumen to the abomasum, regardless of feeding method, and thus absorption of IgG would be similar between treatment groups. Even if a portion of the meal entered the rumen, the amount would likely be too small to detect a difference in IgG absorption because a high-quality colostrum was fed; calves were fed $200 \mathrm{~g}$ of $\operatorname{IgG}$ in this study, which is double the recommended minimum amount of $100 \mathrm{~g}$ of $\mathrm{IgG}$ for adequate passive transfer of immunity (Godden et al., 2009). Some evidence indicates a possible physiological limit to the amount of IgG can be absorbed due to a limited number of surface receptors; absorption of $\operatorname{IgG}$ is restricted once those receptors are saturated (Leece, 1973; Jaster, 2005; Conneely et al., 2014). Therefore, even if colostrum enters the rumen when fed with an esophageal tube, when a large enough volume of good quality colostrum is delivered, the IgG in the colostrum that reaches the small intestine could be sufficient to saturate the receptors and meet maximal absorption of $\mathrm{IgG}$.

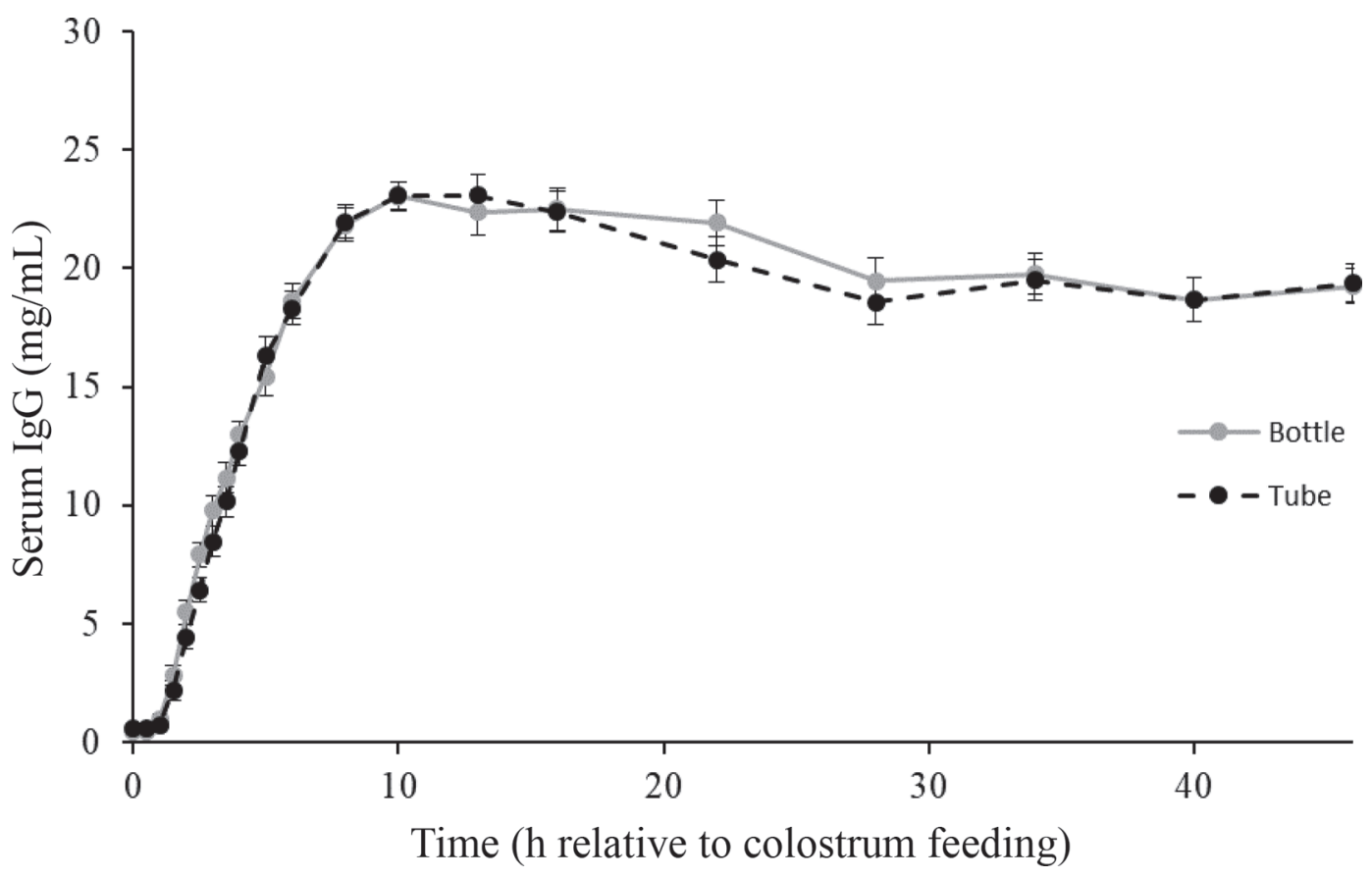

Figure 2. Effect of tube versus bottle feeding colostrum on serum IgG concentrations in newborn calves. The dotted line indicates calves in the tube treatment, and the solid line represents calves in the bottle treatment. Data are LSM \pm SEM, $\mathrm{n}=10$ per group. Treatment effect $(P$ $=0.71)$, time effect $(P<0.0001)$, and treatment $\times$ time interaction $(P=0.92)$. 


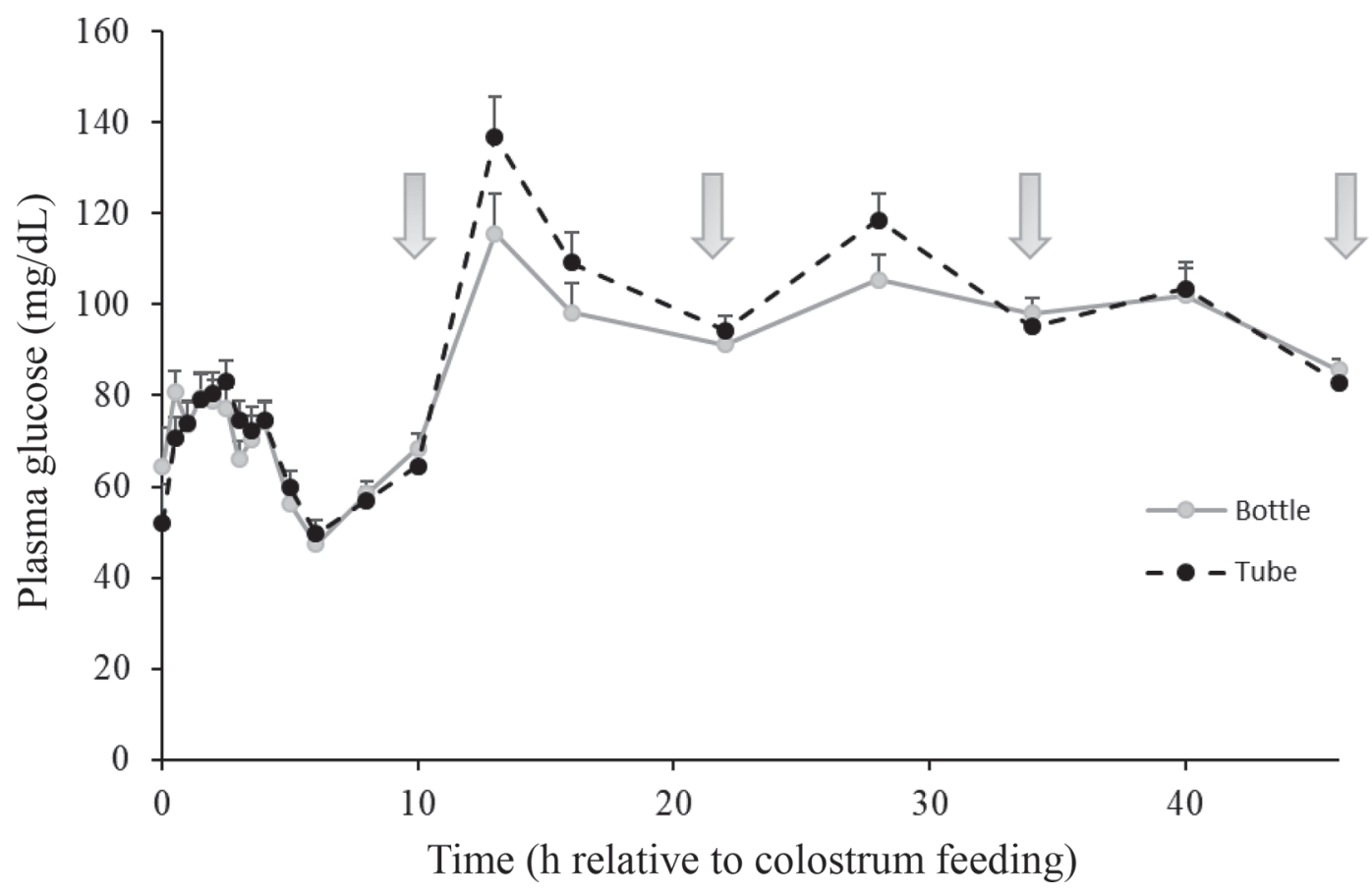

Figure 3. Effect of tube versus bottle feeding colostrum on plasma glucose concentrations in newborn calves. The dotted line indicates calves in the tube treatment, and the solid line represents calves in the bottle treatment. Arrows indicate milk feedings. Data are LSM \pm SEM, $\mathrm{n}=$ 10 per group. Treatment effect $(P=0.49)$, time effect $(P<0.0001)$, and treatment $\times$ time interaction $(P=0.75)$.

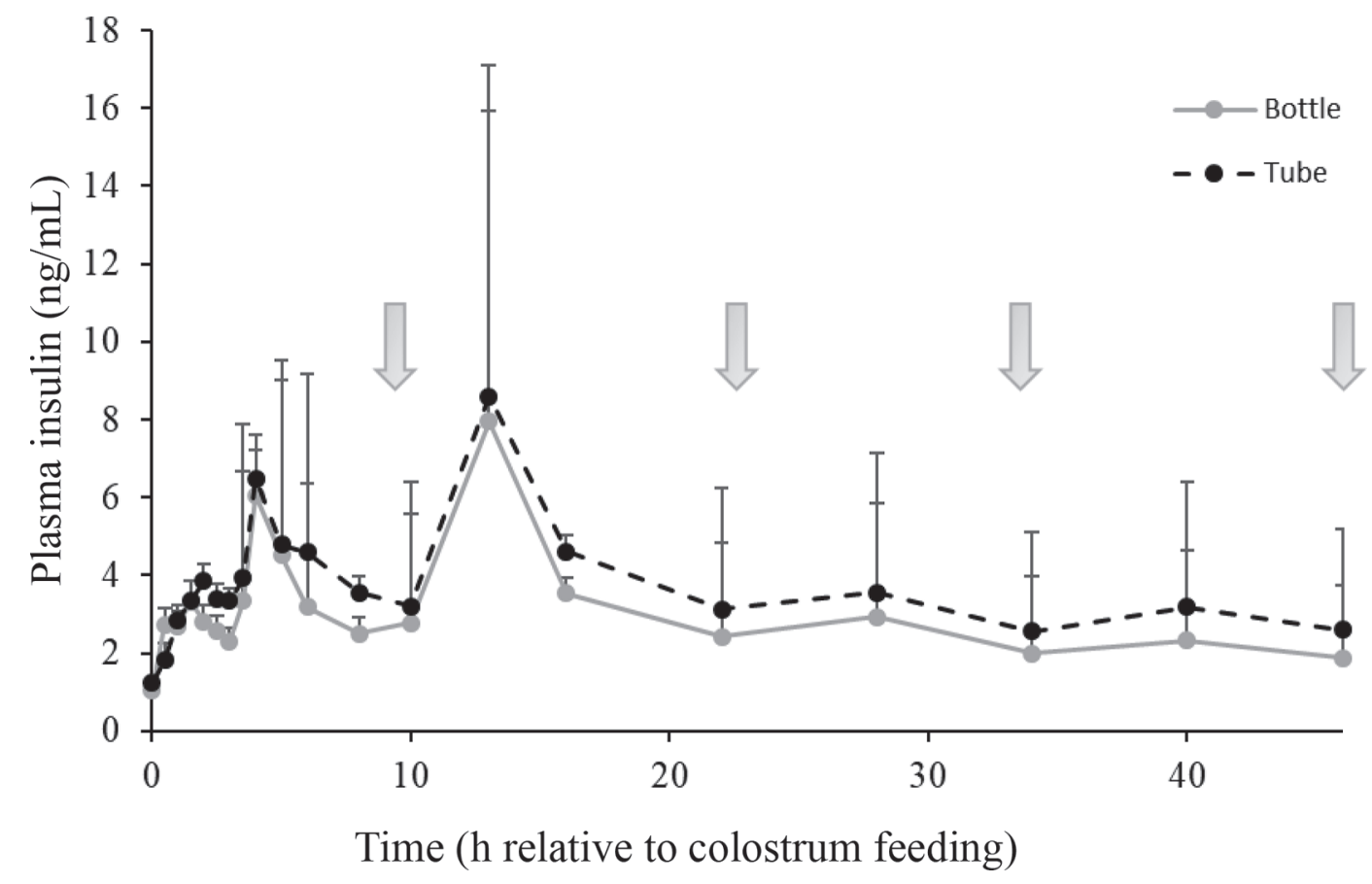

Figure 4. Effect of tube versus bottle feeding colostrum on plasma insulin concentrations in newborn calves. The dotted line indicates calves in the tube treatment, and the solid line represents calves in the bottle treatment. Arrows indicate milk feedings. Data are LSM \pm SEM, $\mathrm{n}=$ 10 per group. Treatment effect $(P=0.12)$, time effect $(P=0.68)$, and treatment $\times$ time interaction $(P=0.58)$. 


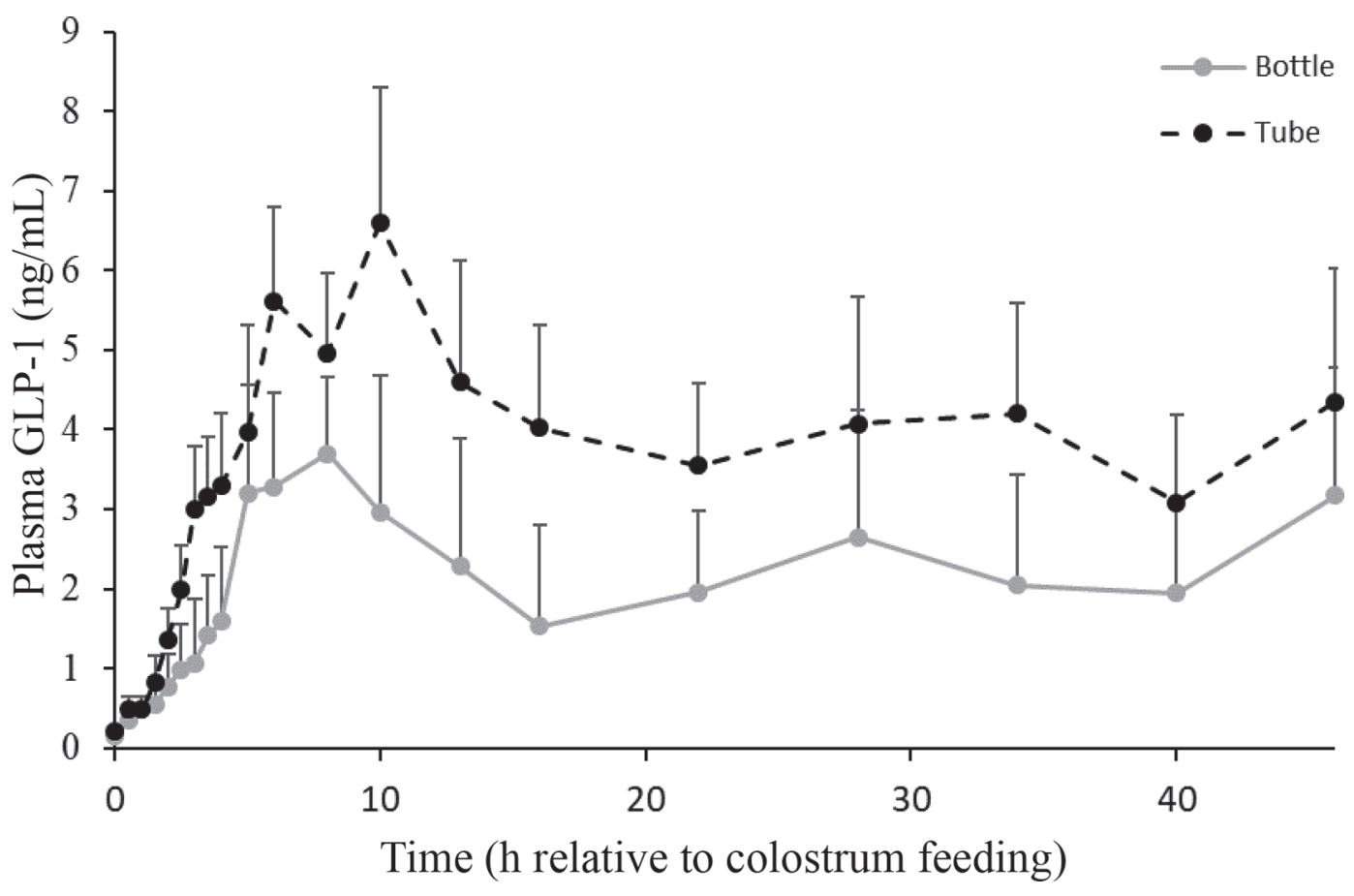

Figure 5. Effect of tube versus bottle feeding colostrum on plasma glucagon-like peptide (GLP) 1 concentrations in newborn calves. The dotted line indicates calves in the tube treatment, and the solid line represents calves in the bottle treatment. Data are LSM \pm SEM, $\mathrm{n}=10$ per group. Treatment effect $(P=0.26)$, time effect $(P<0.0001)$, and treatment $\times$ time interaction $(P=0.38)$.

Although the current study demonstrated that when feeding a large volume of high-quality colostrum feeding method does not affect passive transfer of immunity, if the current study had fed a smaller volume or a lower quality colostrum it is possible that feeding with a bottle would have resulted in increased absorption of IgG, as seen in the Godden et al. (2009) study. This is important to note because the amount of colostrum and quality of colostrum fed varies greatly on farms, and may not be the same as what was fed in this study.

Table 3. Effect of tube versus bottle feeding colostrum on plasma glucose, insulin, and glucagon-like peptide (GLP) 1 and GLP-2 concentrations in newborn calves

\begin{tabular}{|c|c|c|c|c|}
\hline \multirow[b]{2}{*}{ Item $^{1}$} & \multicolumn{2}{|c|}{ Treatment } & \multirow[b]{2}{*}{ SEM } & \multirow[b]{2}{*}{$P$-value } \\
\hline & Bottle & Tube & & \\
\hline Glucose $\mathrm{C}_{\max }(\mathrm{mg} / \mathrm{dL})$ & 125 & 146 & 7.5 & 0.06 \\
\hline Glucose $T_{\max }(h)$ & 22.5 & 17.2 & 3.65 & 0.32 \\
\hline 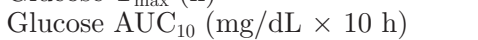 & 714.3 & 833.6 & 31.41 & 0.02 \\
\hline Glucose $\mathrm{AUC}_{46}(\mathrm{mg} / \mathrm{dL} \times 46-10 \mathrm{~h})$ & 3,240 & 3,716 & 164.6 & 0.06 \\
\hline Insulin $\mathrm{C}_{\max }(\mathrm{ng} / \mathrm{mL})$ & 8.3 & 11.0 & 1.28 & 0.16 \\
\hline Insulin $\mathrm{T}_{\max }(\mathrm{h})$ & 9.1 & 9.3 & 1.57 & 0.91 \\
\hline Insulin $\mathrm{AUC}_{10}(\mathrm{ng} / \mathrm{mL} \times 10 \mathrm{~h})$ & 32.4 & 45.0 & 3.60 & 0.02 \\
\hline Insulin $\mathrm{AUC}_{46}(\mathrm{ng} / \mathrm{mL} \times 46-10 \mathrm{~h})$ & 102.0 & 133.9 & 14.77 & 0.14 \\
\hline GLP-1 $C_{\max }(\mathrm{ng} / \mathrm{mL})$ & 6.2 & 7.9 & 1.76 & 0.50 \\
\hline GLP-1 $\mathrm{T}_{\max }(\mathrm{h})$ & 19.9 & 9.9 & 4.08 & 0.99 \\
\hline GLP-1 AUC $_{10}(\mathrm{ng} / \mathrm{mL} \times 10 \mathrm{~h})$ & 22.7 & 42.3 & 9.54 & 0.16 \\
\hline GLP-1 $\mathrm{AUC}_{46}(\mathrm{ng} / \mathrm{mL} \times 46-10 \mathrm{~h})$ & 77.5 & 143.0 & 45.02 & 0.32 \\
\hline GLP-2 $\mathrm{C}_{\max }(\mathrm{ng} / \mathrm{mL})$ & 3.9 & 4.3 & 0.66 & 0.74 \\
\hline GLP-2 $\mathrm{T}_{\max }(\mathrm{h})$ & 9.4 & 11.2 & 0.97 & 0.20 \\
\hline GLP-2 AUC $_{10}(\mathrm{ng} / \mathrm{mL} \times 10 \mathrm{~h})$ & 21.8 & 32.6 & 4.68 & 0.12 \\
\hline GLP-1 AUC $_{46}(\mathrm{ng} / \mathrm{mL} \times 46-10 \mathrm{~h})$ & 63.5 & 87.1 & 28.82 & 0.26 \\
\hline
\end{tabular}

${ }^{1} \mathrm{C}_{\max }=$ maximum serum concentration; $\mathrm{T}_{\max }=$ time of maximum concentration observed; $\mathrm{AUC}_{10}=$ area under the concentration-time curve until $10 \mathrm{~h} ; \mathrm{AUC}_{46}=$ area under the concentration-time curve from 10 to $46 \mathrm{~h}, \mathrm{n}$ $=10$ per group. 


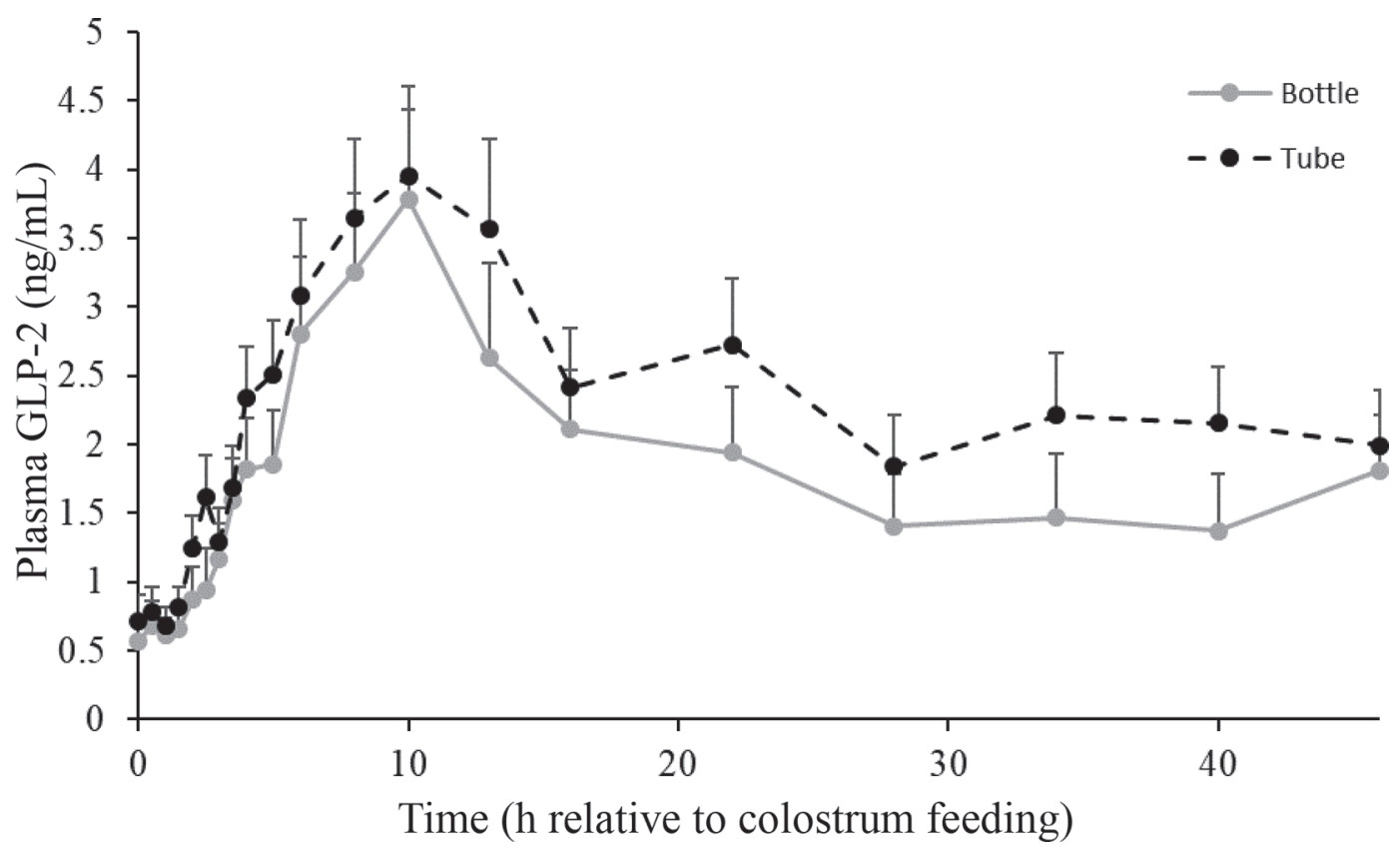

Figure 6. Effect of tube versus bottle feeding colostrum on plasma glucagon-like peptide (GLP) 2 concentrations in newborn calves. The dotted line indicates calves in the tube treatment, and the solid line represents calves in the bottle treatment. Data are LSM \pm SEM, $\mathrm{n}=10$ per group. Treatment effect $(P=0.43)$, time effect $(P<0.0001)$, and treatment $\times$ time interaction $(P=0.22)$.

Many farms may feed 3 or more liters, but most likely less than $200 \mathrm{~g}$ of $\operatorname{IgG}$ is being delivered. When feeding a lower quality colostrum, it is possible there could be benefits to feeding with a bottle and this warrants further investigation. In addition, it is important to consider the way that tube feeding is conducted. In the current study, no adverse effects were seen with using a tube; however, it was conducted appropriately and safely. Therefore, on farm considerations for tube versus bottle feeding should include volume and quality of colostrum, as well as how the handler is tube feeding. If good-quality colostrum is fed and the tubing is done appropriately, than either method is appropriate on farm.

\section{Glucose and Insulin}

Previous studies have only measured serum IgG concentrations when comparing feeding colostrum with a tube or a bottle, but colostrum contains many other beneficial components. Theoretically, feeding with an esophageal tube could result in colostrum entering the rumen, which would delay lactose absorption from colostrum and thus decrease glucose and insulin concentrations in the blood. Interestingly, the opposite was observed in this study; overall AUC for glucose and insulin was higher for calves fed with a tube compared with a bottle.
To differentiate between the effect of the colostrum feeding and the effect of the milk feeding on glucose and insulin, both concentrations and AUC were assessed before the first milk meal and after the first milk meal. Glucose and insulin concentrations increased after colostrum feeding; however, they increased considerably more after the first milk meal. The smaller response in glucose and insulin to colostrum feeding is likely due to colostrum containing only $2.7 \%$ lactose compared with milk, which contains $5.0 \%$ lactose (Godden, 2008). Other studies (Hammon and Blum, 1998; Kühne et al., 2000) have shown a similar effect, where colostrum feeding did not lead to a large response in glucose concentrations, but they observed a large response in glucose after the first milk meal. Moreover, that response was greater in calves that received colostrum compared with calves that did not.

In the current study, tube feeding increased glucose and insulin AUC before the first milk meal. Both treatments consumed the same colostrum, and thus lactose; therefore, the treatment effect on glucose is not due to different amounts of glucose being consumed. Therefore, this difference could be primarily attributed to tube-fed calves consuming their colostrum meal faster than the bottle-fed calves. Because glucose AUC before the first milk feeding was negatively correlated with time to consume the colostrum, it is likely that the faster feeding time resulted in higher glucose AUC for 
tube-fed calves. Several mechanisms could explain why feeding time could result in a difference in plasma glucose concentration.

It is reasonable, however, to assume that less glucose is being used by the gut tissues before entering the blood in tube-fed calves. In beef cattle, it has been shown that only $70 \%$ of starch digested in the small intestine appears in the blood, with the remaining $30 \%$ at least partially accounted for by glucose utilization in the small intestine (Richards, 1999). Then, it is possible that, in the current study, the initial appearance of colostrum in the small intestine occurred more quickly when fed with a tube, therefore expediting glucose entry into the bloodstream and reducing the amount of glucose that can be used by the gastrointestinal tract compared with bottle-fed calves. In addition, previous research suggested that suckling could increase salivary flow and the subsequent swallowing of pregastric enterases, which may have affected results in the current study (de Passillé et al., 1993).

As mentioned previously, tube-fed calves consumed their colostrum faster than bottle-fed calves and had higher glucose AUC before the first milk meal. They also consumed half a liter more milk than the bottle-fed calves during the first milk meal. Glucose AUC before the milk feeding was also positively correlated with the amount of milk consumed, and the amount of milk consumed was negatively correlated with time to consume the colostrum meal. These results indicate that calves who consumed their colostrum faster had higher glucose AUC and drank more milk in the first meal. This relationship is consistent with a speculation that less glucose would have been used in the gastrointestinal tract in tube-fed calves than bottle-fed calves. If fewer nutrients are being used in the gastrointestinal tract, perhaps demand for nutrients in the gut is higher in tube-fed calves. Thus, although the results of the current study do not fully explain the mechanism behind the higher glucose AUC in tube-fed calves, reduced opportunity for glucose utilization by the gastrointestinal tract might provide one possible explanation.

As mentioned previously, insulin AUC before the milk feeding was also higher for tube-fed calves. Because glucose and insulin were positively correlated, it is likely the treatment difference in insulin before the first milk meal is due to increased plasma glucose concentrations. However, another factor that could be contributing to the treatment difference in insulin is absorption of insulin from colostrum. Colostrum contains large amounts of insulin, with the first colostrum milking containing $65 \mu \mathrm{g} / \mathrm{L}$ compared with mature milk that only contains $1 \mu \mathrm{g} / \mathrm{L}$ (Blum and Hammon, 2000). The colostrum powder product used in this study was made from bovine colostrum, and therefore likely contained high levels of insulin. However, insulin content was not measured in the powdered colostrum in this study. A study conducted in neonatal piglets (Shen and $\mathrm{Xu}, 2000$ ) demonstrated that insulin was absorbed throughout the small intestine, but as the piglets aged, absorption shifted specifically to the distal small intestine. Thus, as the gut closes, the ability to absorb insulin decreases. Although this has not been measured in newborn calves, it is possible that insulin is absorbed early in life before gut closure. Any insulin absorption would occur very early after the colostrum feeding; thus, the differences in time to consume the colostrum meal could affect its plasma concentration.

Feeding colostrum through an esophageal tube increased AUC for both glucose and insulin before the first milk meal, but only tended to increase glucose AUC after the milk feeding; it did not affect insulin AUC after the milk feeding even though intake of the first milk meal differed by $0.5 \mathrm{~L}$. This indicates that the effect that feeding method has on plasma glucose and insulin concentrations is most pronounced immediately after the colostrum feeding, and more research would need to be conducted to determine which feeding method is better for glucose status in newborn calves.

\section{GLP-1 and GLP-2}

Although colostrum does not supply large amounts of glucose, it increases gut development in newborns, which increases the absorptive capacity of their gut; thus, they are able to absorb glucose from milk more efficiently (Hammon and Blum, 1997). The gut peptide hormone GLP-1 is associated with insulinotropic effects (Fukumori et al., 2012a), whereas GLP-2 is associated with increased gut development in older animals (Taylor-Edwards et al., 2011). Previous research has not measured these hormones in newborns or in response to colostrum feeding. The current study showed no treatment effect on the plasma concentrations of these hormones but showed a significant time effect for both GLP-1 and GLP-2 after colostrum feeding, indicating that colostrum feeding increases plasma concentrations of GLP-1 and GLP-2. Plasma concentrations of GLP1 and GLP-2 were positively correlated, which agrees with previous research showing these 2 hormones are cosecreted (Burrin et al., 2001). The AUC for insulin and GLP-1 also had a tendency to be positively correlated, suggesting that GLP-1 may have insulinotropic effects in newborn calves, similar to those seen in older calves (Fukumori et al., 2012a). The insulinotropic effect of GLP-1 is a glucose-dependent action in monogastric animals; however, GLP-1 has been shown to increase circulating insulin while decreasing circulating glucose in older calves (Fukumori et al., 2012a). This could 
have occurred in the current study as plasma GLP-1 concentration was positively correlated with the insulin concentration, but not with the glucose concentration.

Abomasal emptying rate tended to be negatively correlated with GLP-1 $\mathrm{T}_{\max }$ in the current study. Because secretion of both GLP-1 and GLP-2 is initiated by nutrients, primarily carbohydrates and lipids, reaching the small intestine, a slower emptying rate would delay the time nutrients are supplied to the small intestine and thus increase the time to reach maximum GLP-1 concentrations (Burrin et al., 2001). The negative correlation between time to consume the colostrum meal and AUC for GLP-1 or 2 before the first milk meal provides further evidence that the timing of nutrient delivery to the small intestine affects the stimulation of GLP response.

\section{CONCLUSIONS}

These results demonstrate that feeding colostrum with either an esophageal tube or nipple bottle are acceptable methods to ensure successful passive transfer of immunity when calves are fed $3 \mathrm{~L}$ of high-quality colostrum. Abomasal emptying rates were not affected by feeding method when this volume of colostrum was fed. Feeding colostrum increased plasma concentrations of glucose, insulin, GLP-1, and GLP-2, but feeding method did not affect plasma concentrations of GLP-1 or GLP-2. Feeding colostrum with an esophageal tube increased plasma concentrations of glucose and insulin, but its implications are not clear from the current study. In addition, feeding colostrum with a tube also increased consumption of the first milk meal, and this warrants further investigation.

\section{ACKNOWLEDGMENTS}

The authors thank the funding support provided by Alberta Milk (Edmonton, AB, Canada), The Saskatoon Colostrum Co. Ltd. (Saskatoon, SK, Canada), and the Natural Sciences and Engineering Research Council of Canada (Ottawa, ON, Canada). The authors also thank Breevliet Ltd. (Wetaskiwin, AB, Canada) for allowing us to conduct this experiment on their farm and all of their assistance throughout the experiment.

\section{REFERENCES}

Beam, A. L., J. E. Lombard, C. A. Kopral, L. P. Garber, A. L. Winter, J. A. Hicks, and J. L. Schlater. 2009. Prevalence of failure of passive transfer of immunity in newborn heifer calves and associated management practices on US dairy operations. J. Dairy Sci. 92:3973-3980.

Berndtson, W. E. 1991. A simple, rapid and reliable method for selecting or assessing the number of replicates for animal experiments. J. Anim. Sci. 69:67-76.
Blum, J. W., and H. M. Hammon. 2000. Colostrum effects on the gastrointestinal tract, and on nutritional, endocrine and metabolic parameters in neonatal calves. Livest. Prod. Sci. 66:151-159.

Burrin, D. G., Y. Petersen, B. Stoll, and P. Sanglld. 2001. Glucagonlike peptide 2: a nutrient-responsive gut growth factor. J. Nutr. 131:709-712.

Cant, J. P., V. N. Walsh, and R. J. Geor. 2006. Obtaining information on gastric emptying patterns in horses from appearance of an oral acetaminophen dose in blood plasma. Pages 69-83 in Nutrient Digestion and Utilization in Farm Animals: Modelling Approaches. CABI Publishing, Wallingford, Oxfordshire, UK.

CCAC. 1993. Guide to the Care and Use of Experimental Animals. Vol. 1. 2nd ed. Canadian Council on Animal Care, Ottawa, ON, Canada.

Chamorro, M. F., P. H. Walz, D. M. Haines, T. Passler, T. Earleywine, R. A. Palomares, K. P. Riddell, P. Galik, Y. Zhang, and M. D. Givens. 2014. Comparison of levels and duration of detection of antibodies to bovine viral diarrhea virus 1, bovine viral diarrhea virus 2 , bovine respiratory syncytial virus, bovine herpesvirus 1 , and bovine parainfluenza virus 3 in calves fed maternal colostrum or a colostrum-replacement product. Can. J. Vet. Res. 78:81-88.

Chapman, H. W., D. G. Butler, and M. Newell. 1986. The route of liquids administered to calves by esophageal feeder. Can. J. Vet. Res. 50:84-87.

Chigerwe, M., D. M. Coons, and J. V. Hagey. 2012. Comparison of colostrum feeding by nipple bottle versus oroesophageal tubing in Holstein dairy bull calves. J. Am. Vet. Med. Assoc. 241:104-109.

Conneely, M., D. P. Berry, J. P. Murphy, I. Lorenz, M. L. Doherty, and E. Kennedy. 2014. Effect of feeding colostrum at different volumes and subsequent number of transition milk feeds on the serum immunoglobulin G concentration and health status of dairy calves. J. Dairy Sci. 97:6991-7000.

de Passille, A. M. B., R. Christopherson, and J. Rushen. 1993. Nonnutritive sucking by the calf and postprandial secretion of insulin, CCK, and gastrin. Physiol. Behav. 54:1069-1073.

Fukumori, R., T. Mita, T. Sugino, T. Obitsu, and K. Taniguchi. 2012a. Plasma concentrations and effects of glucagon-like peptide-1 (736) amide in calves before and after weaning. Domest. Anim. Endocrinol. 43:299-306.

Fukumori, R., T. Sugino, H. Shingu, N. Moriya, Y. Hasegawa, M. Kojima, K. Kangawa, T. Obitsu, S. Kushibiki, and K. Taniguchi. 2012 b. Effects of calcium salts of long-chain fatty acids and rumen-protected methionine on plasma concentrations of ghrelin, glucagon-like peptide-1 ( 7 to 36 ) amide and pancreatic hormones in lactating cows. Domest. Anim. Endocrinol. 42:74-82.

Godden, S. 2008. Colostrum management for dairy calves. Vet. Clin. North Am. Food Anim. Pract. 24:19-39.

Godden, S. M., D. M. Haines, K. Konkol, and J. Peterson. 2009. Improving passive transfer of immunoglobulins in calves. II: Interaction between feeding method and volume of colostrum fed. J. Dairy Sci. 92:1758-1764.

Hammon, H. M., and J. W. Blum. 1997. Prolonged colostrum feeding enhances xylose absorption in neonatal calves. J. Anim. Sci. $75: 2915-2919$.

Hammon, H. M., and J. W. Blum. 1998. Metabolic and endocrine traits of neonatal calves are influenced by feeding colostrum for different durations or only milk replacer. J. Nutr. 128:624-632.

Holst, J. J. 2000. Gut hormones as pharmaceuticals from enteroglucagon to GLP-1 and GLP-2. Regul. Pept. 93:45-51.

Inabu, Y., A. Saegusa, K. Inouchi, S. Koike, M. Oba, and T. Sugino. 2017. Plasma concentrations of glucagon-like peptide 1 and 2 in calves fed calf starters containing lactose. J. Dairy Sci. 100:93619371.

Jaster, E. H. 2005. Evaluation of quality, quantity, and timing of colostrum feeding on immunoglobulin $\mathrm{G}$ absorption in Jersey calves. J. Dairy Sci. 88:296-302.

Kaske, M., A. Werner, H. J. Schberth, J. Rehage, and W. Kehler. 2005. Colostrum management in calves: effects of drenching vs. bottle feeding. J. Anim. Physiol. Anim. Nutr. (Berl.) 89:151-157.

Kühne, S., H. M. Hammon, R. M. Bruckmaier, C. Morel, Y. Zbinden, and J. W. Blum. 2000. Growth, performance, metabolic and endo- 
crine traits, and absorptive capacity in neonatal calves fed either colostrum or milk replacer at two levels. J. Anim. Sci. 78:609-620.

Leece, J. G. 1973. Effect of dietary regimen in cessation of uptake of macromolecules by piglet intestinal epithelium (closure) and transport into blood. J. Nutr. 103:751.

Lombard, J. E., F. B. Garry, S. M. Tomlinson, and L. P. Garber. 2007. Impacts of dystocia on health and survival of dairy calves. J. Dairy Sci. 90:1751-1760.

MacPherson, J. A., H. Berends, L. N. Leal, J. P. Cant, J. Martin-Tereso, and M. A. Steele. 2016. Effect of plane of milk replacer intake and age on glucose and insulin kinetics and abomasal emptying in female Holstein Friesian dairy calves fed twice daily. J. Dairy Sci. 99:8007-8017.

Marshall, T. S., P. D. Constable, S. S. Crochik, and T. Wittek. 2005. Determination of abomasal emptying rate in suckling calves by use of nuclear scintigraphy and acetaminophen absorption. Am. J. Vet. Res. 66:364-374.

Nouri, M., and P. D. Constable. 2006. Comparison of two oral electrolyte solutions and route of administration on the abomasal emptying rate of Holstein-Friesian calves. J. Vet. Intern. Med. 20:620-626.

Quigley, J. D., C. J. Kost, and T. M. Wolfe. 2002. Absorption of protein and IgG in calves fed colostrum supplement or replacer. J. Dairy Sci. 85:1243-1248.

Richards, C. J. 1999. Influence of small intestinal protein on carbohydrate assimilation and metabolism in beef cattle. PhD Diss. Dept. Animal and Food Sciences, Univ. Kentucky, Lexington.

Schaer, S., M. Herrli-Gygi, N. Kosmeas, H. Boschung, and A. Steiner. 2005. Characteristics of acetaminophen absorption in healthy unweaned calves as an indirect measurement of the oroduodenal transit rate of liquid meals. J. Vet. Med. A Physiol. Pathol. Clin. Med. 52:325-332.

Sen, I., P. D. Constable, and T. S. Marshall. 2006. Effect of suckling isotonic or hypertonic solutions of sodium bicarbonate or glucose on abomasal emptying rate in calves. Am. J. Vet. Res. 67:13771384 .

Sharifi, K., W. Grunberg, S. Soroori, M. Mohri, and M. S. AhrariKhafi. 2009. Assessment of the acetaminophen absorption test as a diagnostic tool for the evaluation of the reticular groove reflex in lambs. Am. J. Vet. Res. 70:820-825.

Shen, W., and R. Xu. 2000. Gastrointestinal stability and absorption of insulin in suckling pigs. Comp. Biochem. Physiol. A Mol. Integr. Physiol. 125:389-401.

Steinhoff-Wagner, J., S. Gors, P. Junghans, R. M. Bruckmaier, E. Kanitz, and C. C. Metges. 2011. Maturation of endogenous glucose production in preterm and term calves. J. Dairy Sci. 94:5111-5123.

Taylor-Edwards, C. C., D. G. Burrin, J. J. Holst, K. R. Mcleod, and D L. Harmon. 2011. Glucagon-like peptide-2 (GLP-2) increases small intestinal blood flow and mucosal growth in ruminating calves. J. Dairy Sci. 94:888-898.

Trotz-Williams, L. A., K. E. Leslie, and A. S. Peregrine. 2008. Passive immunity in Ontario dairy calves and investigation of its association with calf management practices. J. Dairy Sci. 91:3840-3849.

Wallace, M. M., B. D. Jarvie, N. R. Perkins, and K. E. Leslie. 2006. A comparison of serum harvesting methods and type of refractometer for determining total solids to estimate failure of passive transfer in calves. Can. Vet. J. 47:573-575. 